\title{
ADVANCING BORDER THINKING THROUGH DEFAMILIARISATION \\ IN UNCOVERING THE DARKER SIDE OF COLONIALITY AND \\ MODERNITY IN SOUTH AFRICAN HIGHER EDUCATION
}

\section{Z. Waghid*}

e-mail:waghidz@cput.ac.za

\author{
L. Hibbert* \\ e-mail: hibbertl@cput.ac.za
}

*Senior Phase and Further Education and Training Department

Cape Peninsula University of Technology

Cape Town, South Africa

\section{ABSTRACT}

This article reports on a case study in which illustrations were used as prompts as a way of disrupting automatic colonised thoughts. The aim of this was to awaken deep rather than surface responses in pre-service teachers, and to introduce reflexivity as a means of introducing border thinking, which we saw as having the potential to impact positively on identity formation. Identity formation is of crucial importance for pre-service teacher education given that the system has not transformed significantly to accommodate diversification and inclusivity as a social and human rights issue. The article draws on theories designed to counteract the coloniality/modernity imaginary; it introduces border-thinking through defamiliarisation with the aim of enhancing senses of agency among pre-service teachers. Students were encouraged to draw themselves in relation to the global world. Following on from this, students participated in blogs in which they discussed their own drawings while also commenting on the drawings of others. The analysis is partially content-focussed and partially discourse-focussed. The findings reveal that the intervention prompted students to review their identities reflexively in relation to globalisation. The results show, firstly, that the intervention had positive results in terms of enhancing students' senses of agency, and, secondly, they demonstrate, or suggest, possible ways in which the defamiliarisation process can lead to border thinking, thereby addressing coloniality.

Keywords: border thinking, abyssal thinking, decoloniality, defamiliarisation, pre-service teacher education

\section{INTRODUCTION}

The recent call for decolonising higher education in South Africa, emanating from the 2015 \#Rhodesmustfall campaign, has led to specific demands from students - and many academics - to implement a curriculum that critically centres Africa and the subaltern. More specifically, 
this means treating African discourses as a point of departure, in the sense of addressing not only content but languages and methodologies of education and learning, and only examining western traditions in so far as they are relevant to the African experience (Rhodes Must Fall collective statement of demands, March 2015). According to Luckett (2016, 418), coloniality presupposes that cultural or structural change ends up mostly as reproduction if deliberate reflexivity is not engaged with by the institutional powers that be.

Andreotti (2011), drawing on the seminal thoughts of Maldonado-Torres (2004), Quijano (2000), and Mignolo (2000), posits that modernity depends very much on coloniality for its existence. Mignolo (2000) calls for the use of border thinking as an epistemic principle that aims to break the modernity and coloniality imaginary. Such an epistemic principle aims to make the darker side of modernity and the coloniality of power visible. Within the notion of the coloniality/modernity imaginary is the coloniality of power. More specifically, the coloniality of power is an expression coined by Quijano (2000) to name the structures of power, control, and hegemony that have emerged during the colonialist and modernist eras. The coloniality of power in this regard categorises individuals in society according to racial, political, and social hierarchies. Through the coloniality of power in contemporary society the subaltern is produced: individuals are made to feel inferior to the Eurocentric paradigm in terms of racial classification, knowledge, and cultural systems.

One of the invisible places in contemporary society - including in South Africa - in which the coloniality of power functions, as Mignolo $(1999,241)$ postulates, is the domain of epistemology, in which knowledge is conceived of as stemming exclusively from Europe (Mignolo 1999, 241). It is largely this dominance of a European world view in South African higher education that prompted the student protests named the \#Rhodesmustfall campaign. This situation and view is further vindicated in a recent study conducted by Sayed, Motala and Hoffman (2017), which found that pre-service teachers at five South African universities in the Western Cape have had extremely limited exposure to multiple understandings of Africa and its complex histories, including its education histories, and in this regard are largely isolated from broader southern debates. In this way, cognitive injustice continues to pervade higher education institutions in South Africa.

Mignolo's (2000) notion of border thinking may be used to advance cognitive justice in higher education institutions in South Africa. Border thinking stems from the same family as “Double critique” and “Creolization” (Mignolo 2000, 84). More specifically, Du Bois’s “Double consciousness” (1994), Wright’s “Double vision” (1993), Anzaldua’s “new mestiza consciousness" (1987), Calderon and Saldivar's “Borderlands theory” (1991). The notion of "border thinking" is aimed at critically reflecting on the imaginary of the modern world system 
from the perspective of the coloniality of power (Mignolo 2000, 84). The key configuration of border thinking is the disruption of dichotomies, more specifically, as Mignolo (2000, 85) poignantly states, "thinking from dichotomous concepts rather than ordering the world into dichotomies”. In other words, it is aimed at breaking away from the Eurocentric epistemological perspectives, poignantly stated by Mignolo’s (2000) philosophy of “I am where I think”.

Creating decolonised spaces for teachers and learners has the potential to assist them further in uncovering the hidden racial existential conditions routinely re-enacted within educational systems in South Africa and abroad. By implication, the creation of equitable spaces, under the guide of the concept of decoloniality, may begin to assist university educators and students further in disrupting their conceptions of the "Western ideal" imposed on them as “colonised” through a Eurocentric paradigm. This could act as a means of transforming what has become known as epistemic violence, and advancing cognitive justice in not only within universities but also in schools and colleges in South Africa.

We see the call for decolonisation in South African higher education as requiring the cultivation of a "decolonised space”, in which localised cultural and social recollections are expressed and embedded within non-Western epistemologies. We therefore argue for defamiliarisation as a transformative pedagogy (see Waghid and Hibbert 2018) for possibly advancing Mignolo's (2000) notion of border thinking as a means of disrupting the invisible places that exist in contemporary society in South Africa. Adopting such a pedagogy in educational institutions in South Africa may lead to disrupting, as Maldonado-Torres (2004) claims, the “epistemic privilege” foregrounded by Boaventura de Souza Santos’s (2007) notion of “abyssal thinking”, in other words, disrupting, a modern western thinking that distinguishes between two radical sides of social reality in terms of two realms, which he refers to as "this side of the line", that is, the colonialist ideologies in contrast to "that side of the line" or the colonised. According to Santos $(2007,45)$, “the other side of the line” vanishes as reality becomes non-existent, and is indeed produced as non-existent. Building on Santos's (2007) notion of abyssal thinking, we further argue that one's perception of modernity becomes habitualised to the extent that one's actions become "unconsciously automatic", as literary theorist Viktor Shklovskij (1965) maintained.

This article, building on a previous study (see Waghid and Hibbert 2018), aims to address the colonised, more specifically, the invisible residual and resistant underpinnings of coloniality embedded within teacher education discourses in South Africa. This is done first, by exploring whether defamiliarisation can assist pre-service teachers in reflecting on their own positions in the global society as a means of making the darker side of coloniality/modernity more visible to them. To this end, three discussion questions were posed to guide students' responses in face- 
to-face focus group interviews. Those theoretical orientations which underpin, and led towards, specific questions are discussed in the next section.

\section{THEORETICAL ORIENTATIONS}

\section{The destructive nature of the coloniality/modernity imaginary}

As a philosophical doctrine, modernity's link to Western ideas, principles and ideals is considered as “culture dependent” (Gyekye 1997, 264). Despite the very nature of modernity being considered as “culture dependent” by Gyekye (1997), the western liberal notion of the individual as some sort of entity as one capable of existing and flourishing on its own, unconnected to any community of other individuals, and not bound by cultural, biological or socio-economic and political relationships (Letseka 2000, 181). If it is a given, that our cultures to some extent can exert an influence on our sense of identity and our perception of affiliation with groups with whom we value (Sen 2006, 112), then adopting Sen’s (2006) notion by implication means that the individual stemming from a western or non-western "culture” to an extent values the individual's affiliation, or identifies with western/non-western ideals.

Insofar as modernity can be said to be linked to westernisation, decolonial philosopher Enrique Dussel $(1993,65)$ posits that modernity is essentially and exclusively a European phenomenon for many, in which the underlying notion of modernity surfaces when Europe affirms itself as the "centre” of the global economy. In other words, Europe is the focal point from which modernisation in the global world stems. The western/European notion of the individual premised on the Cartesian philosophy of "I think therefore I am", as an "atomistic being”, further contributes to the colonial/modernity imaginary in contemporary society. The "other face" of modernity - that is, the colonial periphery - is a mere subsequent element of this European self-definition (Dussel 1993).

In the contemporary era modern western thinking, or what Santos (2007) defines as "abyssal thinking” and stemming from the European paradigm, results in the colonial, or "other side of the line”, disappearing as part of the "abyssal line” and essentially considered as nonexistent. The epistemologies produced on the "other side of the line” are essentially excluded because they lie beyond the realm of what is normally accepted in Western/European thought. On the other side of the line - that is the colonial - there is no real knowledge; there are beliefs, opinions, intuitive or subjective understandings which are merely objects for scientific inquiry (Santos 2007, 47). What fundamentally characterises abyssal thinking is the impossibility of the co-presence of the two contrasting realms or sides of the line (Santos 2007). This idea is premised on the western notion that the other side of the line is regarded as "non-existent, 
invisible and dialectic" (Santos 2007, 46).

The subalternisation of knowledge certainly exacerbates cognitive injustice in contemporary society, undermining the knowledge of the “colonial” or subaltern. Santos (2007, 53) claims that global social (in)justice is linked to global cognitive (in)justice. In this regard, achieving social justice would be to achieve cognitive justice, Thus, under the guise of education, we need to value knowledge from both sides of the line, if, in valuing cognitive justice, we are to address social justice.

As Sen $(2006,16)$ states, education "is not just about getting children, even very young ones, immersed in an old inherited ethos". Instead education is "about helping children to develop the ability to reason [deliberate] about new decisions any grown-up person will have to take” (Sen 2006, 160). What we infer from Sen's (2006) argument is that education that leads to the [re]producing of the colonial difference, needs to be disrupted as a means of imagining knowledge from an African perspective.

Thus we contend that curricula which constrain the identity choices and agency of students, in doing so, essentially impact on their learning and ultimately on their life choices. Curricula driven by an agenda that focus primarily on preparing students for the workplace, solely in the interests of advancing economic growth, currently a western ideal, shapes students' identity and knowledge. Bourdieu (1992) certainly acknowledges the societal value of education, in that "if we are not educated, we cannot think much at all”. However, despite Bourdieu's $(1992,40)$ acknowledgement of the societal value of education, education which is not mediated, (re)examined or negotiated carries certain risks in that "if we are educated we risk being dominated by ready-made thoughts”. The fact that students' agencies are constrained by neo-liberalist curricula further undermines their capacity to co-construct or produce new knowledge. In this regard, cognitive justice is undermined by students' lack of agency in such constrained curricula. What follows is an argument based on the premise that, through cognitive injustice, a majority of students are excluded, less likely to develop a sense of what it means to live well, less likely to be able to compare different ways of life, and also less likely to choose a good life for themselves (Unterhalter and Walker 2007, 245). Equipping university students with the competencies and capacities to reflect on alternative choices about how to live is a crucial component of providing them with substantive freedom and real opportunities in their own life choices (Brighouse 2000, 80).

Gyekye (1997, 234) defines “colonial mentality” as the "colonised mind” which has been skewed under the influence of colonial thought categories, which in turn results in the tendency of the "colonial” to regard foreign cultural products as of much greater worth than those of her or his indigenous culture and knowledges. For the "colonised mind”, the indigenous cultural 
products are in fact spurned by the individuals with colonial mentality, to the extent that some individuals even, and unashamedly, show an aversion to speaking local languages (Gyekye 1997, 234). Certainly, for South Africans to break free from the intellectual leash of the modernity/colonial imaginary requires a reorientation of their collective “colonised” mind towards an unbiased, evaluation of indigenous African knowledge through education.

Dussel $(1993,76)$ called for a [re]examining of the inherent notion of modernity as a means of disrupting "the impossibility of the co-presence of the two contrasting sides of the line”. For Dussel $(1993,76)$ the realisation of modernity in contemporary thought "no longer lies in the passage from its abstract potential to its 'real', European, embodiment”. Instead the realisation of modernity lies in what Dussel $(1993,76)$ sees as a process "that will transcend modernity", more specifically, what he terms as "trans-modernity", in which both "modernity and its negated alterity (the colonial) co-realise themselves in a process of mutual creative fertilisation”. What we infer from Dussel's (1993) notion of modernity within the higher education context is that there needs to be a pedagogy - which we argue for - that, through defamiliarisation, comes to be situated within the realm of transmodernity in which "cohabituation” is possible between modernity and alterity. For there to be a co-presence between the two contrasting sides of the line, the need for an epistemic principle such as Mignolo's (2000) border thinking, which aims to break the modern/ colonial imaginary, is certainly needed in South African education discourses (Andreotti 2011).

\section{Border thinking through defamiliarisation}

Shklovskij (1965) claimed that, after we have seen an object several times, we begin to recognise it to the extent that our perceptions become "habitualised". We accept the object at face-value without seeing the deeper meaning behind the object itself hence we cannot say anything significant about it (Shklovskij 1965). Our habits therefore become "automatized" to the degree that we do not see, for instance, the abyssal lines that obscure the rich indigenous knowledge that exists in the contexts in which we find ourselves. The means to uncovering the subconscious mind as if some conscious person is present during the process of defamiliarisation, by implication means that it is as if a third person is present. In this regard, defamiliarisation disrupts one’s “automised” perceptions or experiences unconsciously in distinct educational or social contexts. In other words, one begins to de-automatise one's experiences or perceptions of the world at large through a unique lens, or third-party's lens.

Delpit (2012 in Nichols 2017, 191) argues that constantly focusing on student weaknesses, rather than on their strengths, brings with it the "dis-identification” experienced by non-English first language and/or culturally marginal students. In the interests of equity, Nichols $(2017,182)$ 
argues in favour of creating "transitional spaces for articulation practice" in which difference is not erased, but articulated, embracing and nurturing a fluidity of subjectivity - "web-like" and "multiple” - as Nichols $(2017,188)$ says, "as cultural[ly] alternative, which is characterised by uncertainty and ambivalence”. This is done through introducing defamiliarisation in a process of advancing border thinking, namely an outsider's critique of all dominant discourses which are inherently hegemonic, and which need to be viewed from a subjective, geopolitically contextualised perspective.

Defamilarisation, in advancing border thinking (Mignolo 2013, 132), further calls for a means for doing away with knee-jerk, surface understandings and perspectives. This can be done, as this study shows, by affording students opportunities to illustrate/represent their personal views artistically and their stances towards the notion of globalisation in their own particular contexts. Such a pedagogical space opens up the possibility of searching for alternative articulation practices, which introduces the idea of "lingering" on necessary perceptual contradictions with the aim of stimulating border thinking. Mignolo (2013, 130) describes this as "delinking”, i.e. a delinking from the grand narratives of capitalism, communism and socialism-communism, as well as the opponents of these ideologies and systems, namely Enlightenment politics (liberalism, republicanism and political economy). Only once students are delinked from the grand narratives of ideological thinking can border thinking set in (Mignolo 2013, 136). How we set up this particular study, and to what degree the delinking process was successful for students, is covered in the sections which follow.

\section{METHODOLOGY}

As an interpretive methodology, defamiliarisation serves as a means to provoking one's thoughts by making the familiar strange (Waghid and Hibbert 2018). By implication this would assist researchers in critically examining and uncovering the hidden meanings of students' social and cultural experiences in their particular contexts (Waghid and Hibbert 2018). In this regard, defamiliarisation as an interpretive methodology functions as a means to enabling students and educators to look beyond familiar, dominant narratives, by cultivating in themselves and others critical reflection and deconstruction of taken-for-granted perspectives (Waghid and Hibbert 2018).

Through the process of defamiliarisation, pre-service teachers were required and encouraged to illustrate artistically how they see themselves in the global environment, and to reflect, collaboratively interpret, and critique their own views and the views of others. The discussion, facilitated by us, was in the form of online group blogs on the university's e-learning platform system, namely Blackboard. Students were required to submit to us their individual 
illustrations. This was followed by the online group blog interaction which comprised of between five to six students per group. The purpose of the online discussion was to ascertain and explore students' lived experiences as African students within the global environment. The students' illustrations were analysed using inductive content analysis through the Computer Assisted Qualitative Data Analysis Software (CAQDAS), ATLAS.ti.

The sample population of this study was formed by the cohort of fourth-year BEd Further Education and Training (FET) students. The sample population who indicated their willingness to participate in the project were $(n=25)$ students, which constituted a total number of $(n=4)$ online focus groups. Data were captured through the students' online comments on the blogs. The participants were informed in class that their participation was voluntary, anonymous and confidential. Also, ethical clearance was acquired from the faculty's ethics research committee, adhering to the ethical considerations of the study.

The following discussion prompts were used to guide the students' responses in the faceto-face focus group interviews:

- Explain what is happening in your illustration.

- Comment on the ease of use and usefulness of defamiliarisation as a teaching tool

- Would you implement defamiliarisation at the schools where you will be teaching?

These prompts provided an open-endedness in terms of responses, which was intentional. We used the findings from our analyses of a sample of students' illustrations, together with the reflective blog comments on the e-learning platform system, Blackboard. The sample illustrations from the sample of students selected are found in the section that follows.

The collected responses were used to ascertain the students' experiences of the defamiliarisation activity and to evaluate the relative accuracy of our interpretations of the symbolic representations not visible or explicit in the illustrations. The data collected from students in the blog format were analysed in terms of content as well as discourse features. Attention to discourse features adds to "thick description" of the data and adds another window of perception to the analysis. Finally, the results of our interpretations were run by students as a form of validity testing. An interpretation of (student) verified findings is presented below.

\section{RESULTS}

\section{Students' explanations of their illustrations}

In Image 1, student LAP of group 1 on the online group blog, regarding his illustration, displays 
instances in which he disrupts the coloniality of power in terms of epistemology, cultural systems and modernity. He comments regarding his conception and view of knowledge; he sees his briefcase as a symbol of knowledge in assisting him in advancing in contemporary society. This is corroborated by his comments on the blog:

"The brief case is a symbol of all the knowledge that I have gained through the years and how these experiences are important in my journey and how this will help me move forward.”

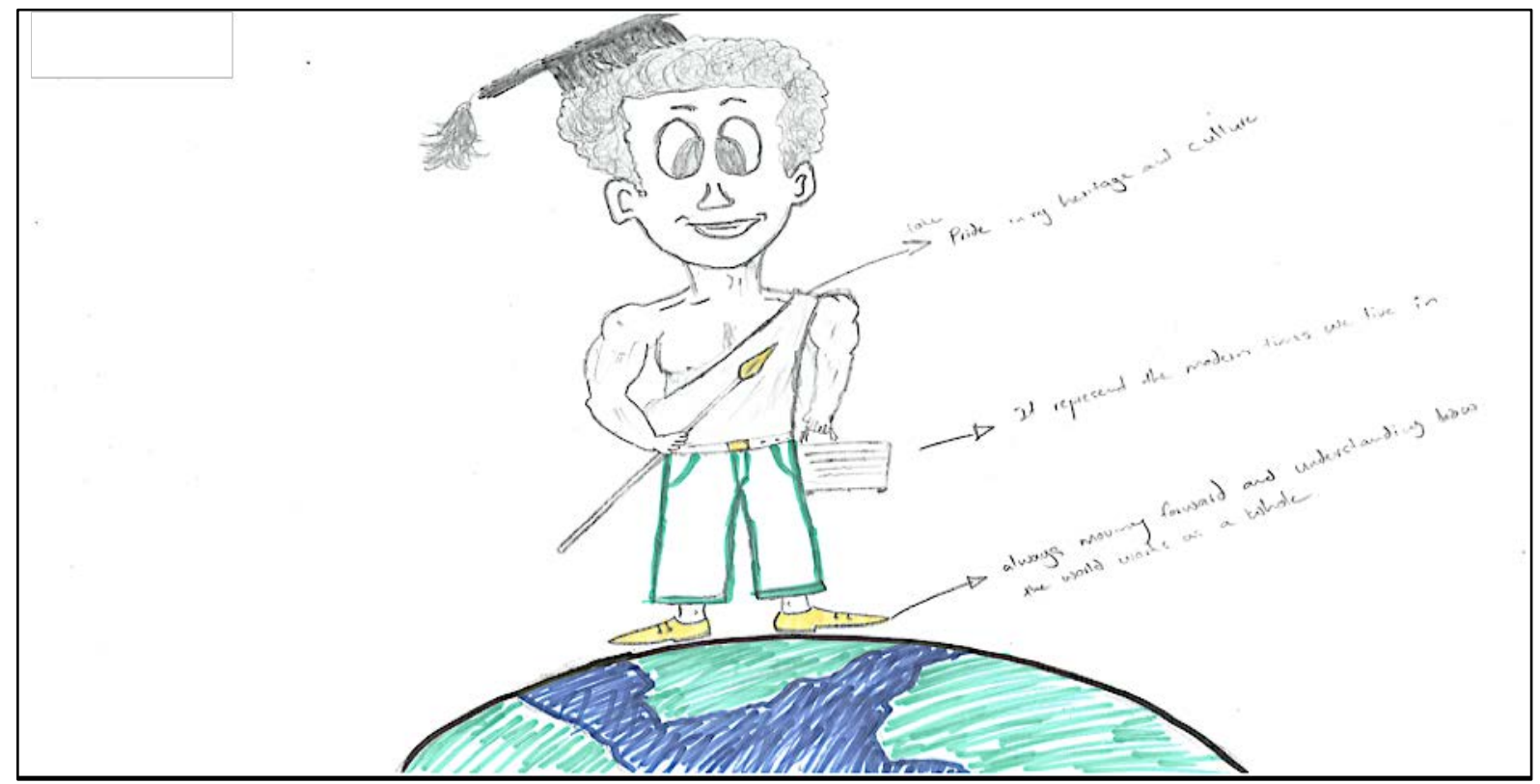

Image 1: Student LAP

He acknowledges the influence of modernity as well, represented by his modern attire in his illustration. In this regard, the individual in the image is seen wearing both the traditional animal skin with a spear, which represents his culture and heritage and trousers with formal shoes which signifies the blend of modernity with African culture. We saw this as the student's symbolic representation of the contemporary modern era in which the student finds himself situated, a context in which he acknowledges both African culture and his identity with modernity. This is substantiated by his comments in the online blogs:

"This is me embracing my culture and religion which is my identity.”

Within the notion of modernity, he sees himself strongly positioned within a global context, possibly due to the (empowering) level of education that he has acquired, or sees himself as having acquired, in his tertiary studies in his blog comment:

"I see myself as someone who has the world on my feet and I am able to make use of every opportunity that is presented to me.” 
He does not disregard the importance of modernity but instead acknowledges its relevance to his context. In this regard, it can be argued that the defamiliarisation process assisted him to reach this insight. He is disrupting, as Gyekye $(1997,234)$ says, the/his “colonised” mind, in that he acknowledges his own cultural worth instead of dismissing it as "inferior" within modernity.

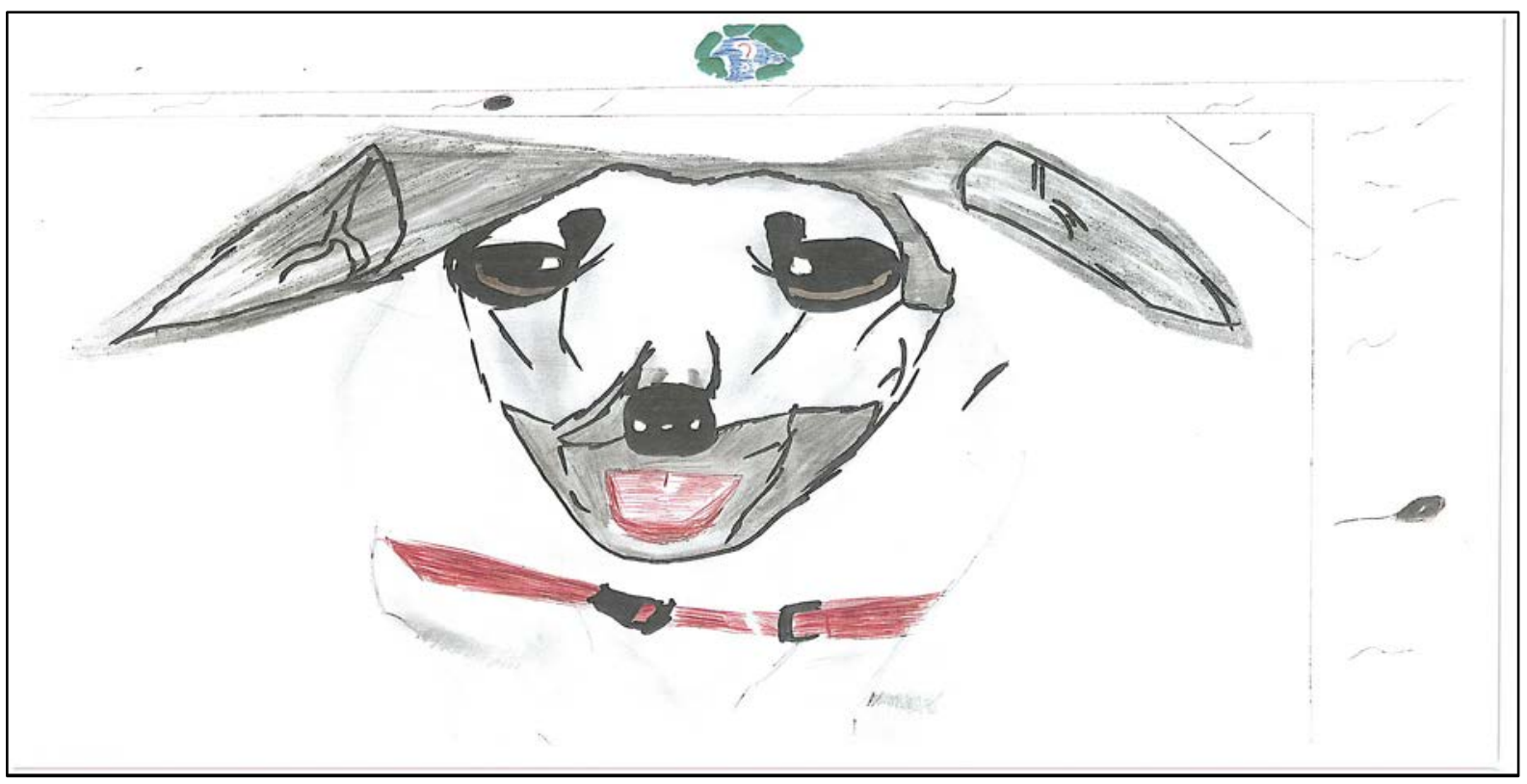

Image 2: Student SAD

In Image 2, student SAD of Group 1 portrays a contrasting image to the illustration by student 1. From his blog comments, commensurate with his illustration within the notion of coloniality of power, instances of modernity, race, cultural systems and a further underlying aspect of politics emerge. Student SAD's illustration of a dog is indicative of how he sees himself, more specifically as an underdog, a status which he links to race, as confirmed by his comments in the blog:

"I see myself in South Africa as a Caucasian male in terms of the global economy is that of an under-dog."

In addition, the student sees himself as an African underdog as confirmed in his blog comments as inferior in many ways. Student SAD's comment regarding himself as "inferior" further vindicates his perception of the hegemonic power structures that continue to categorise Africa as the subaltern. This is also confirmed in student SAD’s comment in the blog:

"The reason for the [t]he world globe being portrayed without Africa, is because of the fact that, in a global view, Africa is not showcased.” 
The red collar on the dog has further meaning. He uses this to symbolise the political and social constraints to achieving success in contemporary society as confirmed by his comments on the blog:

"I find myself, constrained and limited in many ways to achieve certain things."

This political constraint may be linked to the status quo in South Africa in which the current democratically elected government is marred with instances of corruption and maladministration. This is further corroborated by another student (ZN) in Group 3:

"To me, the use of words, such as inflation, foreign debt, corruption and inflation are to show how all these words affect me and are one of the things that take place in our everyday lives."

Although, student SAD's illustration is aimed at assisting him in reflecting on his current position within the global environment, it is very much rooted in South African historical significances, confirmed by his comments in the blog regarding the rings in the illustration:

"The holes in the table with darkened rings signifies, firstly my age as a South African, and secondly the rings of age of our countries somewhat dark past.”

The coloniality of power in student SAD's illustration therefore depicts instances of modernity, race and cultural systems both from a subaltern perspective and in terms of a formerly “apartheid/colonial” perspective. This is further corroborated by student JRL in Group 1 in her blog comment on her illustration:

"The picture conveys how I picture myself as a South African citizen in a continuing globalizing world. Instead of joining the future 'movement' we are weighed down by our past and cannot move forward."

The illustration therefore was an opportunity for these students to reflect on the historical significances that continue to undermine South Africa's democratic and economic success, but also to depict how white South Africans are portrayed in the light of modernity/coloniality despite South Africa having had a democracy for more than twenty years. 


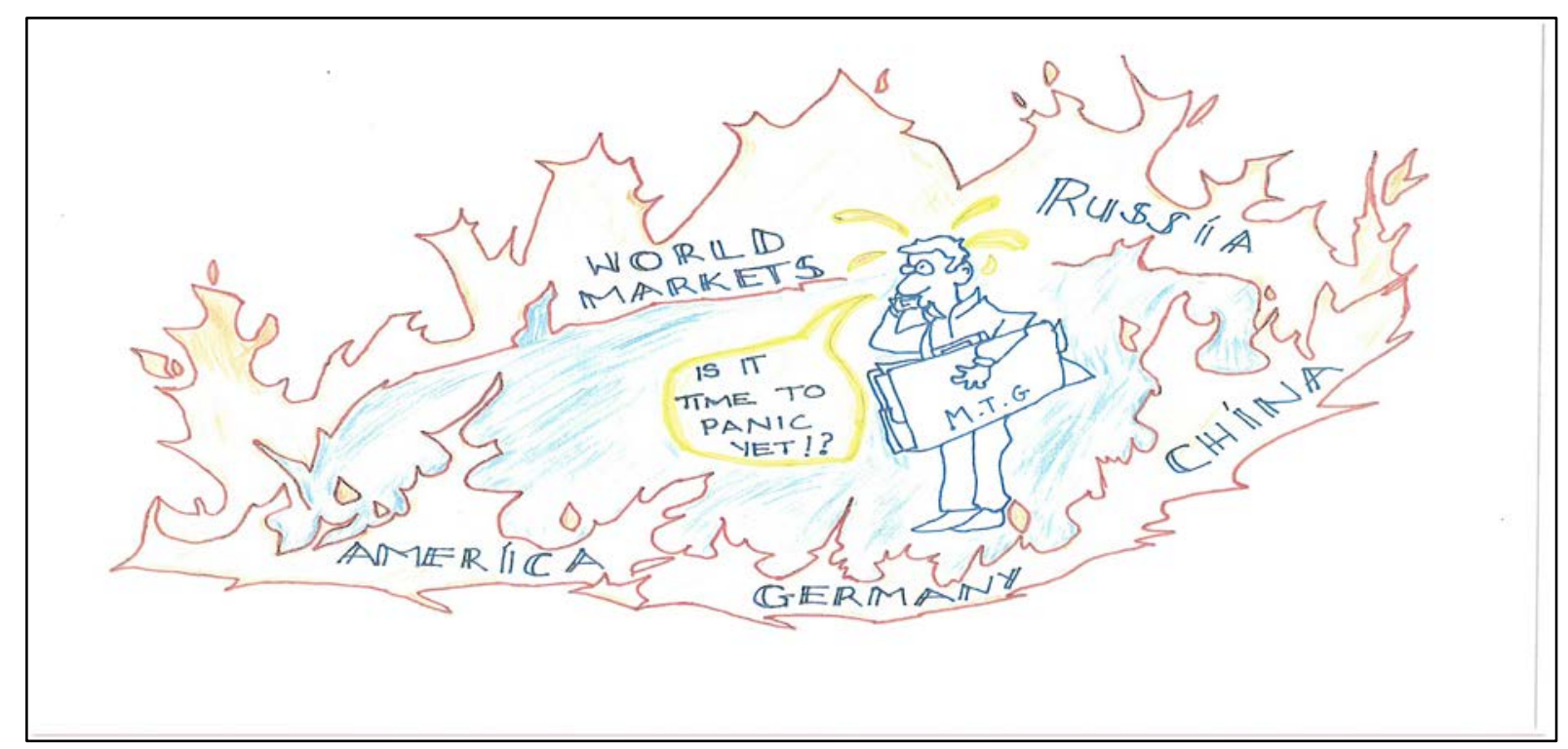

Image 3: Student MTG

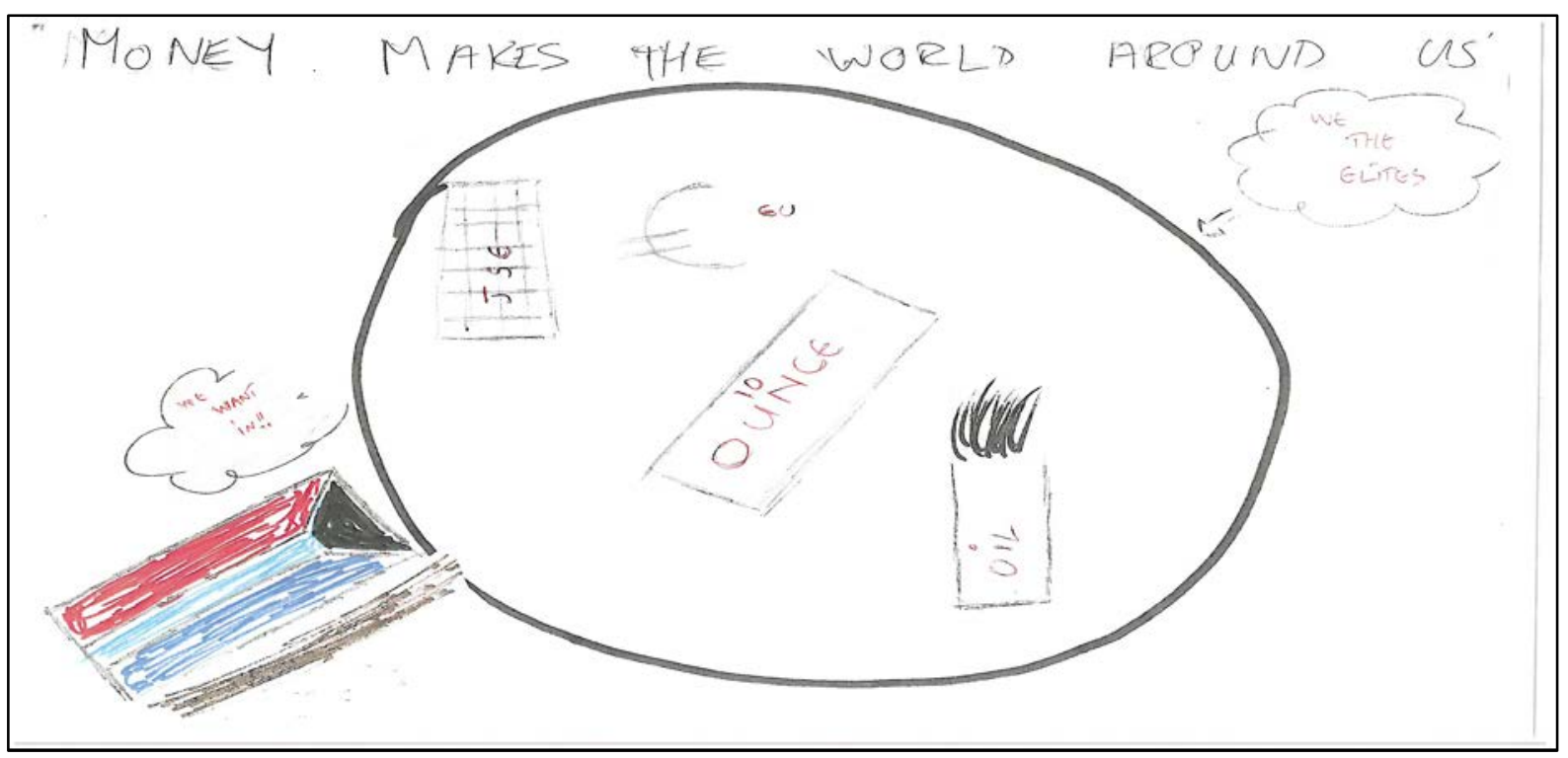

Image 4: Student LN

Students MTG (see Image 3) and student LN (see Image 4) in group 2, illustrate/symbolically depict destructive or undermining instances of modernity and cultural systems in their images. In student MTG's illustration, Africa continues to be depicted as pervaded by the threatening influence of the global market system. The student depicts the dangers of the economic system, using the image of fire to symbolise the economy. In so doing, the student is in turn linking modernity to economic systems whilst reflecting on the need to be more cautious and aware of the impact of the economy on South Africa. Student LN's illustration depicts the "power houses” or Western/European nations in the world's economy and its global dominance, and the effects these economies have on emerging continents, more specifically in terms of "how 
the[y] force the other countries' citizens to be submissive to them" as confirmed by student LN's blog comment. For students MTG and LN, the danger of modernity/coloniality to a large extent influences how the subalterns function in society as subordinates to hierarchical structures in the globalised world, an idea which echoes Dussel's $(1993,65)$ notion in which Europe affirms itself as the "centre" of the global economy. This is further echoed by another student's (TJS in group 1) comment in her blog regarding the transfer of knowledge when describing her illustration:

"The tap running from the globe into the woman's brain represents the transfer of ideas, concepts, innovations and the western way of life."

In this regard, students MTG and LN, like the student whose quote appears above (student TJS), through their illustrations, critically reflect on the challenges Africa as a continent continues to be faced with in modern contemporary society and in developing as a sovereign state. This reflection is supported by two students from group 2 and 4 in their blog comments regarding their illustrations:

"My illustration represents Africa as a whole, and the obstacles that are up in the mountains are the global issues that Africa has [to] deal with in order to become recognized and seen as an equal from a global world view.” (student CM in group 2)

"My illustration is based on how I see myself in the global standpoint as a South African. The illustration shows how the world always separates itself from the African continent; this is because whenever the world speaks of global transformation it seems to exclude Africa from itself.” (student NSN in group 4)

Another student (SG) in group 4 underlines the influence of the coloniality of power on her own schooling career in the sense that South Africans continue to be treated as human capital for the global environment, an idea which resonates with Bourdieu's (1992) acknowledgement of the risk of education:

"The South African schooling system teaches us to be job seekers and employees. We are taught to finish matric, go to universities, get a degree and then find a job.”

The comment of Student JRL, in group 1 (see Image 5) reveals her perception that the majority of South Africans are being excluded from participating in the global economic and social spheres of society:

"My drawing also tries to illustrate South Africans as isolated, poor, weighed down and not being able to join in the rest of the world's thoughts, discussions and development.” 


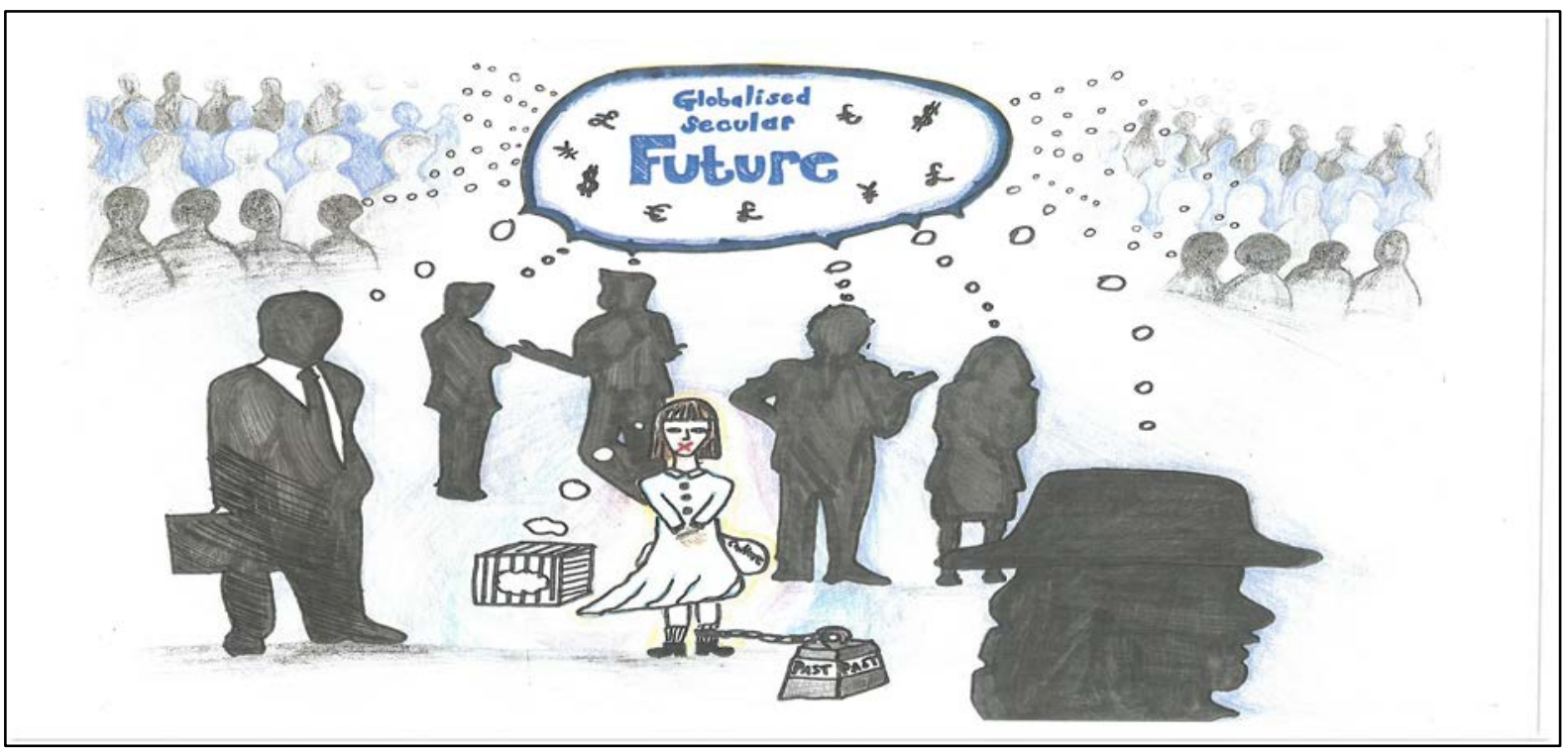

Image 5: Student JRL

The first five images therefore - from the "colonialised" perspective - depict the perpetual social and economic exclusion of Africa as the subaltern in which the invisible lines continue to divide the non-western/European from the western/European. In this regard, it can be argued that the defamiliarisation process assisted these students in reflecting from the "other side of the line" which, as Santos $(2007,46)$ avers, is always considered as "non-existent, invisible and dialectic".

Another student's (ZMM) illustration in group 3 shows a further underlying feature of the coloniality of power, one which is gender-based:

"We are made to feel that women and men are equal but to be frank the global market is created to benefit males the most .... As an African female I am at more disadvantage to a male counterpart who comes from a European country regardless of any qualification that we both may have.”

This is echoed by student TVS in group 1's drawing, albeit depicting disruption towards the coloniality of power:

"The female sign is to show my gender, and that even woman can be well educated, therefore there's a book drawn as well.”

The fact that the student uses the word "even” in her blog comment further vindicates her perception of the role of women in society, particularly in her society, regarding knowledge production. She sees how knowledge itself in society continues to be controlled by the male patriarch. Furthermore, despite many of the students' illustrations depicting in some instances the negative and positive influences of modernity on the South African landscape, some students were shown to reflect on their own positions and roles in and potential contributions 
to change in society in disrupting the coloniality/modernity imaginary and seem - possibly through the process of creating their illustrations - to feel empowered to do so. For instance:

"I've realized that through my career path, education, I can do a lot to impact my community, my country and maybe even one day the world. It may seem far-fetched right now, but there have so many people before me who have achieved great things, so I believe that I can be a part of that greatness, even if it is a small part.” (student MA in group 2)

“As Africans, we will always be seen as mostly the 'third world' country. This gives me motivation to aim big and achieve the goals I have set for myself. ... my last goal which is rather an important one is to write a book and get it published.” (student SP in group 4)

From these responses it can be argued that, through the defamiliarisation process, the student shows the intention and the need to produce new knowledge instead of being told or taught what to do, which corroborates what we, the authors/researchers, infer as breaking free from the intellectual leash of the modernity/colonial imaginary and thus to them feeling a sense of their own empowerment and agency. Another student felt that the defamiliarisation task assisted her/him in critically self-reflecting on the importance of being “Afrocentric” and on recovering her agency to become Afrocentric:

"We are so rich in resources and opportunities; we should start acting like we are proud of where we come from, where we are and where we're going.” (student TVS in group 1)

With reference to the second prompt, when we asked students to evaluate the ease of use of the pedagogy, and the usefulness of defamiliarisation, several students described defamiliarisation as a journey leading them to "delve deep" into the "psyche" and "into the subconscious" (student JRL in group 1). Another student writes that she likes defamiliarisation as "the learner is forced to make extra effort in determining the meaning of their work.”

The next section expands on the ideas students generated regarding how they feel about using this method in schools where they might teach.

\section{Students' attitudes towards the possible use of defamiliarisation in schools}

Many of the students indicated their willingness to adopt the defamiliarisation pedagogy in their own teaching at the schools where they would teach. Three students confirmed that, from their own experiences of it, they considered that defamiliarisation would assist their learners in expressing themselves due to the way in which it provides a more equitable and inclusive ethos in the classroom:

"I do feel that this method will be beneficial at schools, wherein it creates a platform where learners who struggle conveying their thoughts into a standard literate form, (for e.g. essays, orals or any method where words are the medium of answer) are able to express themselves.” (student JRL in 
group 1).

"This [defamiliarisation] will also allow for inclusion of every person to take place. We need to think of ways to include the more artistically strong child. This is a perfect way in which to so.” (student TVS in group 1).

"Yes. It is very effective in teaching learners how to express themselves." (student LP in group 1).

Furthermore, one student indicated that defamiliarisation places the learner or student at the centre of his/her own learning:

"It's an easy way to get learners involved and placing them in the centre of learning, where they get to express their opinions and views on issues that concern them without being confused and frustrated as to how they will express themselves in words.” (student CM in group 2).

An added benefit of placing learners at the centre of their own learning is that it helps to build community and a sense of belonging:

"This allows learners from different cultures and languages in the classroom to interact and getting to know each and build each other in Africa, going outwards towards the global perspective." (student CM in group 2).

The following six reflections from the students' blog comments show that that they found defamiliarisation to cultivate critical thinking:

"Mostly because I would like to expose my students to the concept of interrupting our automatic perception of what we already know in this way, the learner is forced to make an extra effort in determining the meaning of their work.” (student CJS in group 1).

"In teaching literature, I would implement it because it would allow the learners to distance themselves from feeling a personal connection to the literature and allow them to analyse in a critical manner." (student NSN in group 4).

"I definitely would implement defamiliarisation at the schools where I will teach because I want to produce learners who will be open-minded and who will be able to critically analyse other people’s viewpoints or perspectives.” (student SG in group 4).

"It creates critical thinking and exploring your mind in a different way than any other 'answering method' can.” (student JRL in group 1).

"Using the technique of drawing or painting to get a message across also allows the brain to think critically and keeps the brain active constantly without the teacher or learners having to speak.” (student TVS in group 1).

"Defamiliarisation enables learners to think critically and see things differently because it evokes and drives their interpretative skills.” (student ZN in group 3).

Eight students indicated that what they valued most highly were the opportunities to develop creativity and creative thinking skills through defamiliarisation:

"I know, from working with kids, that it is also relaxing and fun for them to do. It also allows the 
brain to go beyond the boundaries that words bring. And even though I love to write as well, drawing and colours take me to another world, beyond the normal mundane things learners need to do at school.” (student TVS in group 1).

"It will make learners think more and be creative when they come across questions that require them to explain in depth.” (student LP in group 1).

"Implementing defamiliarisation with my learners will enable them to be creative both in the classroom and in the outside world.” (student SG in group 4).

"I can only assume it will create learners who will think further and be creative in their methods to understanding the concepts and world around them.” (student SP in group 4).

"It made me feel creative and that is the general environment I would want in my classes. This would inspire learners to be more inquisitive and curious.” (student ZMM in group 3).

"It is important to take learners away from the norm and introduce more technical and artistic ways to refer to certain objects. In this way an entertaining and fruitful lesson will be achieved." (student BERS in group 3).

"Yes, I would implement defamiliarisation because of its positive aspects, such as allowing for creativity in the classroom and making it possible for learners to express themselves in the best ways they can. This would then make them more interested in the content they need to learn.” (student ZN in group 3).

"The beauty about it is that it enables pupils to be creative and think out of the box so to say." (student LN in group 2).

Two students mentioned that defamiliarisation cultivates learners' cognitive competencies, which may be linked to their own experiences of the pedagogy as confirmed by their blog comments:

"I think that it is an effective teaching tool and could explain foreign concepts to learners which could otherwise be difficult to explain." (student CM in group 2).

"This is a method of learning that can better the work for learners. Colour and shapes will always intrigue the human mind on a level beyond our wildest thoughts.” (student TVS in group 1).

One student thought that defamiliarisation has the potential to assist learners with recalling events in their (learners') lived experiences:

"And if learners are anything like me, they will also remember their drawings and what they learned much more effectively than in the case of writing." (student JRL in group 1).

One student had already implemented defamiliarisation in her own teaching during a teaching practice session:

"I have used defamiliarisation during my teaching practice session in 2017. It proved to be quite effective as learners felt more comfortable drawing something abstract and explaining thereafter rather than writing an essay about the topic.” (student MA in group 2).

From the students' comments on the group blogs, the common understanding among the students of defamiliarisation is that through the creative illustrations it enhanced their cognitive, 
social and teaching presences. Deep social inquiry requires creativity, vision and deliberation (Kurth-Schai and Green 2008, 6; Waghid 2014). By implication it is envisaged through defamiliarisation as a pedagogy that the pre-service teachers in the study would establish classrooms premised on equitable, critical and deliberative learning as a means of cultivating communities of practice inside and outside of the classroom. In this regard, learners in turn would be better prepared in contributing to the economic, cultural and social spheres of society (Waghid 2014; 2016).

\section{Setting in motion border thinking through defamiliarisation - a report on the successes and challenges}

Shklovskij's (1965) concept and process of defamiliarisation have been described, together with its use in this project as a means of disrupting students' "habitualised” perceptions of modernity. Thus, in our project, defamiliarisation, through the use and existence of creative illustrations, together with dialogic critical reflection on these, aimed to uncover the hidden, invisible abyssal lines described by Santos (2007) by making the darker side of modernity/coloniality more prominent or visible to the person from the "third party lens" (Shklovskij 1965). Thus, when the students engaged in the process of defamiliarisation they began to uncover distinct themes subconsciously experienced through the process of illustration, themes that would not have been overtly known to the person, had the person remained in the process of "automatisation". This is further corroborated by Tolstoy in Shklovskij (1965), who submits that the experience itself of creating the illustration is a means to impeding one's automatised perception to the greatest possible effect, produced through the slowness, or gradualness, of the perception. Overwhelming evidence provided in the next section testifies to the successes of this method of learning for this group of students. However, defamiliarisation as a teaching method also presented them with some challenges in terms of time and curriculum constraints, and possible resistance from students to innovation:

"As a creative person, drawing comes easily, although constricted time frames to complete drawings, challenge me. I would like to complete a drawing on my own time, but I understand how that would not always be possible, especially in schools." (student JRL in group 1).

"The only possible issue for using this task as a teaching tool would be the way in which the content or lesson can be brought over to learners in a way that is relevant within the curriculum.” (student $\mathrm{SAD}$ in group 1 ).

"Defamiliarisation will be a difficult concept to implement within the schools that I teach at. This is because it is a difficult concept to bring across to students, as students generally don't take well to new systems and ways of thinking. Students are used to having things follow a system; if things change, then they will try to fight that system by being disruptive and it would take a long time to implement.” (student MTG in group 2). 
"It is very tricky, and will be very tricky to implement, as it is ambiguous in itself." (student LN in group 2).

These quotations demonstrate that students have a very good grasp of the coloniality of power within the education system in which they are asked to perform and transform systems. It also shows that they are realistic about the fact that it is not going to be an easy option to transform the systems into a preferred shape. The successes discussed above however, show that students opted overwhelmingly in favour of defamiliarisation, which leads to the conclusion that border thinking was advanced in the process.

\section{DISCUSSION AND CONCLUDING REMARKS}

The first research question explored whether defamiliarisation has the potential to assist preservice teachers in reflecting on the coloniality of power, a process which was intended to be a means of uncovering the darker sides of coloniality/modernity. In the students' illustrations of how they see themselves in the modern global world, we, the researchers, together with the students, were attempting to explore depictions and conceptions of race, epistemology, cultural systems and experiences of African identities within the realm of the coloniality of power in relation to modernity. With reference to the second major research question: whether the students would implement defamiliarisation as pedagogy in the schools in which they would one day teach, students' responses evidently showed that they had, through the process of completing the tasks described, already progressed significantly on the journey towards border thinking.

For the participants, defamiliarisation broke down habitual responses and exposed binary oppositions, such as solidified perceptions of Africa versus Europe. The global economy was broadly speaking described by some of the students as a continued threat to the sovereignty of the African continent. Personal feelings of heaviness by some of the students in being African is attenuated to the increasing pressures of globalisation on higher education in South Africa.

Broadly-speaking, the task forced students to engage, to spend more time on thinking processes, and to shift their thinking towards objectivity and abstraction. To describe how defamiliarisation causes one's perceptions and ideas about the world to widen, is vindicated by how illustrating "livened" the students' experiences in this study. A further benefit of defamiliarisation noted was putting the learner at the centre, suggesting that defamiliarisation has the potential to be a community-building pedagogy.

The shift to border thinking had a major effect on student identity, as it not only made them remember things, but also moved them forward towards seeing their world and lived experience from different perspectives. This was particularly the case for students who may be 
regarded as socially, linguistically and economically marginal because of the history of racial division in South Africa which has perpetuated disengagement with formal institutional learning. Students' enhanced feelings of agency were expressed in their remarking on the online blogs that they look forward to their role in helping to "mould learners" and saying that they had learned to value their own perceptions. Students saw the tasks as prompting them to be more confident and more empathetic towards diversity and differences in thought patterns. They became more confident - and thus empowered - particularly in problem solving and critical articulation. In other words, the students became "bricoleurs", as Levi-Strauss (1962) would describe the process, with self-reflexivity as part of the interpretation "toolbox".

In this study, defamiliarisation has been shown to be an effective and powerful pedagogy in "de-automatising" the perceptions and experiences of university educators and students in this particular institution. What defamiliarisation further calls for, and which may serve as complementary enquiry, is a "[re]examining of the mechanisms" (Maldonado-Torres 2004, 51) which contribute to the invisibility and subordination of the "colonised", and which may assist higher education educators and students in "searching for invisible faces [rather] than searching for imperial roots” (Maldonado-Torres 2004, 51).

\section{REFERENCES}

Andreotti, V. D. O. 2011. (Towards) decoloniality and diversality in global citizenship education. Globalisation, Societies and Education 9(3-4): 381-397.

Anzaldúa, G. 1987. Borderlands: La frontera (Vol. 3). San Francisco: Aunt Lute.

Bourdieu, P. 1992. An invitation to reflexive sociology. Chicago, IL: Chicago University Press.

Brighouse, H. 2000. School choice and social justice. Oxford: Oxford University Press.

Calderón, H., J. D. Saldívar. (Eds.). 1991. Criticism in the borderlands: Studies in Chicano literature, culture, and ideology. North Carolina: Duke University Press.

Delpit, L. 2012. "Multiplication is for white people": Raising expectations for other people's children. New York: The New Press.

Du Bois, W. E. B. 1994. The souls of Black folk. New York, Avenel, NJ: Gramercy Books

Dussel, E. 1993. Eurocentrism and modernity (Introduction to the Frankfurt Lectures). Boundary 2 20(3): 65-76.

Gyekye, K. 1997. Tradition and modernity: Philosophical reflections on the African experience. Oxford: Oxford University Press.

Kinnamon, Keneth and Fabre. (Eds). 1993. Conversations with Richard Wright. Jackson: University of Mississippi Press

Kurth-Schai, R. and C. R. Green. 2008. Education and democracy. In Encyclopedia of the social and cultural foundations of education, ed. E. F. Provenzo Jr., 1-8. Thousand Oaks, CA: Sage.

Letseka, M. 2000. African philosophy and educational discourse. In African voices in education, ed. P. Higgs, N. C. G. Vakalisa, T. V. Mda and N. T. Assie-Lumumba. Cape Town: Juta.

Levi-Strauss, C. 1962. The savage mind. Chicago, IL: University of Chicago Press.

Luckett, K. 2016. Curriculum contestation in a post-colonial context: A view from the South. Teaching 
in Higher Education 21(4): 415-428. http://dx.doi.org/10.1080/13562517. 2016.1155547

Maldonado-Torres, N. 2004. The topology of being and the geopolitics of knowledge. City 8(1): 29-56. https://doi.org/10.1080/1360481042000199787

Mignolo, W. D. 1999. I am where I think: Epistemology and the colonial difference. Journal of Latin American Cultural Studies 8(2): 235-245.

Mignolo, W. 2000. Local histories/global designs: Coloniality, Subaltern knowledges and border thinking. Princeton, NJ: Princeton University Press.

Mignolo, W. 2013. Geopolitics of sensing and knowing: On (de)coloniality, border thinking, and epistemic disobedience. Confero 1(1): 129-150.

Nichols, P. 2017. "Hopeful” directions for writing centres in South Africa: From safe spaces to transitional sites of articulating practices. Stellenbosch Papers in Linguistics Plus (SpilPlus) 53: 182-194.

Quijano, A. 2000. “Colonialidad del Poder y Classificacion Social.” Journal of World-Systems Research 6(2): 324-386.

Rhodes Must Fall. 2015. Rhodes Must Fall Statements. The Johannesburg Salon (9): 6-19.

Santos, B. de Souza. 2007. Beyond Abyssal thinking: From global lines to ecologies of knowledges. Review 30(1): 45-89.

Sayed, Y., S. Motala and N. Hoffman. 2017. Decolonising initial teacher education in South African universities: More than an event. Journal of Education 68: 59-92.

Sen, A. 2006. Identity and violence: The illusion of destiny. New Delhi: Penguin Books India.

Shklovskij, V. 1965. Art as technique. Translated by L. T. Lemon and M. J. Reis. In Russian formalist criticism, ed. L. T. Lemon and M. J. Reis, 3-24. Lincoln, NE: University of Nebraska Press (Original work published in 1917).

Unterhalter, E. and M. Walker. 2007. Conclusion; capabilities, social justice, and education. In Amartya Sen's capability approach and social justice in education, ed. M. Walker and E. Unterhalter. New York: Palgrave Macmillan.

Waghid, Z. 2014. (Higher) education for social justice through sustainable development, economic development and equity. South African Journal of Higher Education 28(4): 1448-1463.

Waghid, Z. 2016. A pedagogical approach to socially just relations in a Grade 11 Economics class. South African Journal of Education 36(2): 1-18.

Waghid, Z. and L. Hibbert. 2018. Educational Research for Social Change 7(1): 60-77. http://dx.doi. org/10.17159/2221-4070/2018/v7i0a5 